\title{
Pemanfaatan Fentin Asetat di Tambak Sebagai Moluksida Trisipan (Telescopium telescopium)
}

\author{
Anshar Haryasakti ${ }^{1}$ dan Kaharuddin ${ }^{2}$ \\ 1 Program Studi Ilmu Kelautan, Sekolah Tinggi Pertanian Kutai Timur \\ Jl. Soekarno-Hatta, Sangatta, Kutai Timur, email: haryasaktia@yahoo.com \\ 2 Program Studi IImu Kelautan, Sekolah Tinggi Pertanian Kutai Timur \\ Jl. Soekarno-Hatta, Sangatta, Kutai Timur, kaharikl02@gmailcom
}

\begin{abstract}
This study aims to determine the effect of Fentin acetate $60 \%$ with active ingredients fontain acetate is a chemical compound as eradicator of molluscs community as pests in aquaculture pond systems. One of species belongs to molluscs community is Telescopium telescopium capable of thriving on ponds media which is high in organic content and as a competitors for organism which is the function as decomposers and provider of natural food in water pond. Due to designation of fentin acetate to suppress population growth of Telescopium telescopium, the focus of this research was to determine the best concentration and to see the fhysiology response on each treatment. This research used completely randomized design (CRD) and the data were analyzed using analysis of variance ANOVA. The result showed there were significant correlation between Telescopium-telescopium with fentin acetate dosages $60 \%$. Based an average comparison of soaking duration with fentin acetate dosages 4 ppm, 6 ppm and 8 ppm, it was concluded that $8 \mathrm{ppm}$ dosages was the most efficient to control the populations of Telescopium telescopium pest..
\end{abstract}

Keywords: Fentin acetate, Telescopium telescopium, Molluscicide, Pond.

\begin{abstract}
ABSTRAK
Penelitian ini bertujuan untuk mengetahui pengaruh Fentin asetat $60 \%$ dengan bahan aktif fonten asetat merupakan senyawa kimia pemberantas komunitas moluska yang merupakan hama pada budidaya sistem tambak. Salah satu spesies dari komunitas moluska adalah Telescopium telescopium yang mampu berkembang dengan pesat pada media tambak yang tinggi bahan organik dan menjadi pesaing bagi organisme yang berfungsi sebagai pengurai dan penyedia pakan alami dalam kolom perairan.Melihat peruntukan dari fentin asetat untuk menekan perkembangan populasi trisipan, maka penelitian ini fokus untuk mengetahui konsentrasi yang terbaik dan melihat respon fisikologis pada tiap perlakuan. Penelitian menggunakan metode Rancangan Acak Lengkap (RAL) dan data dianalisis dengan menggunakan analisis sidik ragam ANOVA Hasil analisis sidik ragam ANOVA menunjukkan ada hubungan signifikan antara Telescopium telescopium dengan dosis fentin asetat $60 \%$. Berdasarkan perbandingan rata-rata lama waktu perendaman dengan dosis fentin asetat 4 ppm, 6 ppm, dan 8 ppm, disimpulkan bahwa dosis 8 ppm mampu mengontrol populasi hama Telescopium telescopium paling efisien.
\end{abstract}

Kata kunci: Fentin asetat, Trisipan, Molusida, Tambak

\section{Pendahuluan}

Dewasa ini untuk melindungi tambak usaha tani dari serangan hama dan penyakit, sebagian besar petani tambak masih mengandalkan penggunaan pestisida kimia yang dapat diperoleh dengan mudah di pasaran. Sejak digulirkannya kebijakan deregulasi di bidang pendaftaran pestisida pada tahun 2001, dimana jumlah dan jenis pestisida yang 
beredar di pasaran semakin meningkat, sampai tahun 2010 jumlah pestisida yang terdaftar untuk pertanian secara luas mencapai 2.628 formulasi (Kementan, 2011).

Berdasarkan buku pedoman umum skrining pestisida tahun 2010, menjelaskan bahwa fentin asetat merupakan bahan aktif yang dapat digunakan menanggulangi serangan hama siput trisipan diarel tambak (Munajat, 2011). Sebagai bahan kimia aktif, selain berfungsi memberantas komunitas moluska jenis trisifaan, juga berdampak pada udang atau ikan dalam tambak serta lingkungan perairan jika tidak terkontrol dengan benar, sehingga diperlukan aturan dosis pemakaian yang sesuai prosedur. Penelitian ini bertujuan untuk melihat pengaruh pemberian moluksida berbahan aktif fentin asetat dengan konsentrasi berbeda dan melihat respon fisikologis trisipan.

Keong bakau adalah deposit feeder, menggunakan extensible snout untuk menelan lumpur dan detritus dari permukaan endapan lumpur pada saat surut. Dan Dye (1986) dalam Houbrick (1991) menyatakan bahwa Keong bakau makan saat surut.Menurut Ramamoorthi dan Natarajan (1973) dalam Houbrick (1991) di habitat alaminya (di permukaan lumpur muara Vellar Porto Novo, India), ini bereproduksi di permukaan lumpur daerah perairan dangkal dari April Juli. Populasi telur keong bakau dapat mencapai 50.000 telur dengan diameter telur $1250 \mathrm{~mm}$ Telur tiap individu dikelilingi oleh fluida, albumen, dan transparan. Larva keong bakau bebas berenang di perairan. Larva ini menetas setelah 96 jam ditelurkan (Ramamoorthi dan Natarajan 1973 dalam Houbrick( 1991). Keong bakau menyukai tempat lahan terbuka dan banyak sinar matahari substrat lumpur halus di tengah hutan.Keong bakau merupakan moluska asli mangrove yang dapat ditemukan di bagian tengah hutan mangrove.Moluska asli alami memilih hutan mangrove sebagai tempat satusatunya tempat hidup. Genangan air yang cukup luas, kaya akan bahan organik dan terbuka (karena pohon tumbang) disukai oleh keong bakau (Budiman, 1991).

Keong bakau sering ditemukan dalam jumlah berlimpah di daerah pertambakan yang berbatasan dengan hutan mangrove, juga pada sungai-sungai dekat dengan daerah pertambakan (Hamsiah 2000). Menurut Soekendarsi et al., (1996) dalam Hamsiah (2000), hewan ini banyak ditemukan di daerah pertambakan dekat dengan mulut sungai dan dapat hidup pada kadar garam 1-2 ppt, hewan lebih banyak membenamkan diri dalam lumpur yang kaya bahan organik daripada di atas substrat lumpur. Houbrick (1991) menyatakan bahwa individu bakau sering berkelompok. Kehadiran keong bakau di pertambakan tidak alami, karena adanya campur manusia yang membuat tambak sebagai tempat yang disukai oleh keong.Suasana tambak yang baik untuk pertumbuhan pakan memperbesar keberhasilan aktivitas reproduksi dan rendahnya musuh alami atau penyakit, sehingga dapat meninggikan populasi keong bakau (Budiman 1991).Selama musim kering dan periode tidak aktif, keong bakau sering berkelompok dan berlindung di bawah bakau, suhu ekstrim dapat mengakibatkan kematian yang tinggi. Meskipun suhu tinggi kemungkinan 
dapat menyebabkan kematian, hewan ini dapat bertahan pada periode kekeringan. Budiman (1991) melaporkan bahwa hewan ini dapat bertahan lebih dari enam bulan, meskipun tidak terendam air laut. Pola sebaran pada tingkat jenis maupun marga moluska di bakau tidak punya pola tetap. Pola persebaran akan bertambah dengan adanya kebiasaan migrasi dalam pola hidup.

Cangkang keong bakau berbentuk kerucut, panjang, ramping, dan agak mendatar pada bagian dasarnya. Warna cangkang coklat keruh, coklat keunguan, coklat kehitaman, lapisan luar cangkang dilengkapi garis spiral yang sangat dan mempunyai jalur yang melengkung ke dalam. Panjang cangkang berkisar 7,5-11 cm (Barnes 1974 dalam Hamsiah 2000). Ukuran cangkang dewasa normal mencapai ukuran 90-100 mm (Houbrick 1991), namun menurut Brand (1974) dalam Houbrick (1991) cangkang keong dapat mencapai 130 $\mathrm{mm}$. Keong bakau dewasa dimakan oleh kepiting (Scylla serrata) dan dimanfaatkan manusia sebagai makanan di Asia Tenggara termasuk Indonesia dan Filipina (Tryon 1882 in Houbrick 1991). Keong bakau yang masih juvenil biasanya dimangsa oleh kepiting bakau, burung, dan mamalia.

Menurut Pablico and Moody (1991) dalam Asep (2011), bahwa fentin asetat adalah senyawa organotin yang berbentuk kristal padat putih digunakan sebagai fungisida, bakterisida, pengawet kayu, fungisida, industri: herbisida, atraktan serangga, nyamuk dan moluskisida.Nama umum adalah Fentin asetat, Nama kimia adalah Triphenyltin asetat, Berat molekul sebesar 409, dan rumus molekul adalah $\mathrm{C}_{20} \mathrm{H}_{18} \mathrm{O}_{2} \mathrm{Sn}$.

Adapun sifat fisik Fentin asetat adalah $\mathrm{H}^{-\mathrm{O}}, \mathrm{H}^{-2}: 5$, titik lebur: $118-122^{\circ} \mathrm{C}$, Kepadatan: $1.55 \mathrm{~g} / \mathrm{cm}^{3}$, suhu penyimpanan: Approx $4^{\circ} \mathrm{C}$, Kelarutan air: $28 \mathrm{mg} / \mathrm{L}\left(20^{\circ} \mathrm{C}\right)$. Pablico and Moody, (1991) dalam Asep (2011) menerangkan bahwa Fentin Asetat 60\% adalah moluskisida racun lambung berwarna putih, berbentuk tepung yang dapat diemulsikan untuk mengendalikan siput trisipan pada budidaya udang dan ikan bandeng di tambak. Keunggulan dari fentin asetat $60 \%$ di antaranya yaitu:

1. Mengandung bahan aktif fentin asetat yang sangat efektif mengendalikan siput terutama sipit trisipan

2. Aplikasi mudah baik dengan ditebar, disemprotkan, atau disiram, ataupun dipercikkan kedalam lahan tambak

3. Tidak berbahaya bagi ikan atau udang yang dibudidayakan

4. Mudah larut dalam air dan relatif stabil terhadap cahaya, suhu dan kondisi lapangan

5. Tetap ampuh baik digunakan di air tawar maupun di air payau

6. Stabil dan efektif pada berbagai kondisi dan ketinggian air

Fentin asetat atau fenton asetat merupakan bahan aktif yang terkandung dalam produk kategori moluskisida dengan merek dagang Besnoid 60 WP (white pouder) untuk memberantas hama dari komunitas spesies Telescopium telescopium pada lahan tambak. 
Konsentasi bahan aktif $60 \%$ fentin asetat yang terkandung dalam satuan kemasan diharapkan mampu membasmi hama lebih cepat dan efektif, seperti halnya teori yang dikemukakan oleh Asep (2011), bahwa keunggulan bahan yang terkandung sangat efektif dalam mengendalikan siput terutama jenis trisipan (Cerithidea cingulata).

\section{Metodologi}

\section{Waktu dan Lokasi}

Pengambilan sampel trisipan di tambak Sungai Bendera, Dusun Kenyamukan, Desa Sangatta Utara, Kabupaten Kutai Timur, seperti ditunjukkan pada peta lokasi Gambar 1. Proses penelitian dan pengolahan data dilakukan di Laboratorium Ilmu Kelautan Sekolah Tinggi Pertanian Kutai Timur. Penelitian ini di mulai bulan November-Desember 2014.

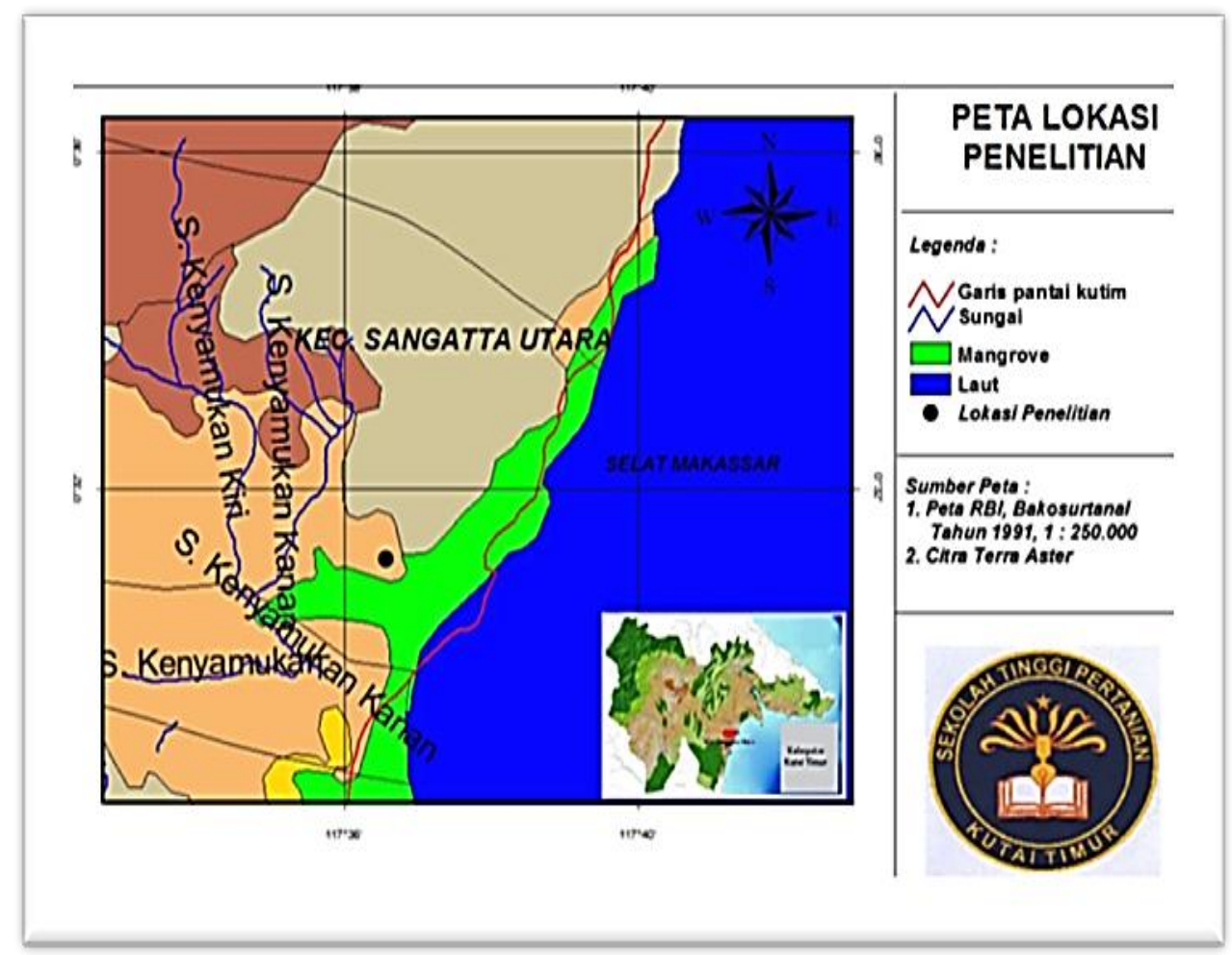

Gambar 1. Lokasi penelitian di tambak Sungai Bendera, Kenyamukan (titik hitam)

\section{Rancangan Percobaan}

Tabel 1. Perlakuan dan jumlah konsentrasi bahan aktif

\begin{tabular}{llc}
\hline No & Macam Perlakuan & Konsentrasi Formulasi \\
\hline 1. & Fentin asetat & $4 \mathrm{ppm}$ \\
2. & Fentin asetat & $6 \mathrm{ppm}$ \\
3. & Fentin asetat & $8 \mathrm{ppm}$ \\
\hline \multicolumn{2}{l}{ Sumber: Data primer penelitian 2015 }
\end{tabular}

Penelitian dilakukan secara eksperimental dengan menggunakan Rancangan Acak Lengkap (RAL), dengan menggunakan fentin asetat $60 \%$ sebagai variabel perlakuan, yang terdiri dengan 3 taraf 4 ppm, 6 ppm, dan 8 ppm, seperti pada Tabel 1, masing-masing 
perlakuan diulang sebanyak 3 kali. Parameter kualitas air dari yang diamati dari media perlakuan adalah salinitas, $\mathrm{pH}$, suhu, dan $\mathrm{DO}$.

Denah rancangan perlakuan dalam penelitian yang akan digunakan seperti pada Gambar 2 dengan perlakuan fentin asetat dan jumlah konsentrasi berdasarkan Tabel 1, dan format pencatatan hasil dari fariabel perlakuan seperti pada Tabel 2.
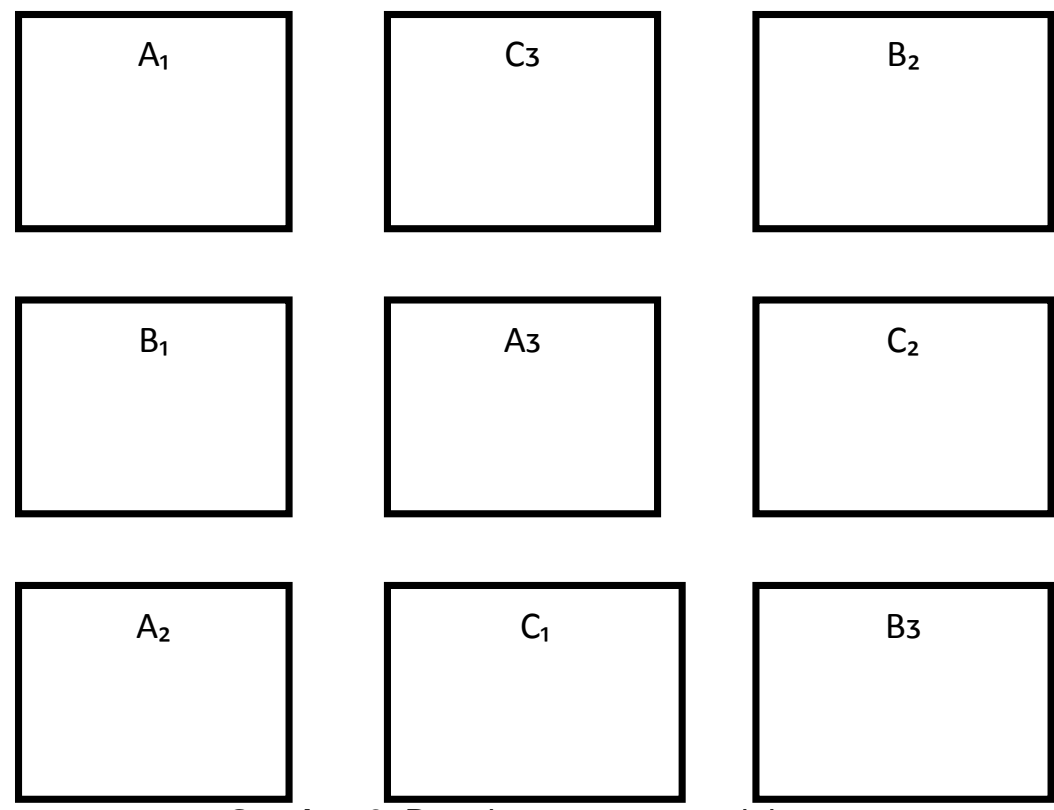

Gambar 2. Denah rancangan perlakuan

Keterangan:A (dosis 4 ppm)

$\mathrm{B}$ (dosis $6 \mathrm{ppm})$

C (dosis $8 \mathrm{ppm})$

Tabel 2. Format pengamatan perbedaan dosis fentin asetat dan tingkat kematian Trisipan

\begin{tabular}{|c|c|c|c|c|c|}
\hline \multirow{2}{*}{ Perlakuan } & \multicolumn{3}{|c|}{ Ulangan } & \multirow{2}{*}{ Jumlah (TA) } & \multirow{2}{*}{ Rata-Rata } \\
\hline & 1 & 2 & 3 & & \\
\hline A & $A_{1}$ & $\mathrm{~A}_{2}$ & $A_{3}$ & & \\
\hline B & $\mathrm{B}_{1}$ & $\mathrm{~B}_{2}$ & $\mathrm{~B}_{3}$ & & \\
\hline C & $\mathrm{C}_{1}$ & $\mathrm{C}_{2}$ & $\mathrm{C}_{3}$ & & \\
\hline
\end{tabular}

\section{Analisis Data}

Pengamatan pengaruh fentin asetat dengan melihat waktu pemberian perlakuan sampai organisme mati dalam hitungan menit. Analisis data pengamatan mortalitas menggunakan persamaan sebagai berikut:

$$
\text { Mortalitas }=\frac{\text { Sindividu mati }}{\text { Stotal individu awal }} \times 100 \%
$$

Data yang terkumpul diuji melalui sidik ragam (ANOVA), apabila ada terjadi perbedaan yang nyata, maka penghitungan dilanjutkan dengan uji BNT (beda nyata terkecil). Eksperimen menggunakan metode rancangan acak lengkap dengan model linier sebagai berikut:

$$
\operatorname{Yij}(t)=\mu+P(t)+\varepsilon(t)
$$

Dimana: $\mathrm{i} \quad=1,2, \ldots \mathrm{n}$; dan $\mathrm{t}=1,2, \ldots \mathrm{n}$ 
Yij $(\mathrm{t})=$ nilai pengamatan pada baris ke-i, kolom ke-j yang mendapatperlakuan ke-t.

$\mu \quad=$ nilai rata-rata umum

$\mathrm{P}(\mathrm{t}) \quad=$ pengaruh perlakuan ke- $\mathrm{t}$

$\mathrm{e}(\mathrm{t})=$ pengaruh galat yang memperoleh perlakuan ke-

\section{Hasil dan Pembahasan}

Jumlah mortalitas trisipan setelah diberi perlakuan, seperti pada Tabel 3., dilanjutkan Gambar 3 mengenai kurva mortalitas trsisipan serta analisis regresi $\mathrm{pH}$ terhadap kematian trisipan, yang tersaji sebagai berikut:

Tabel 3. Mortalitas Trisipan setelah diberi Perlakuan

\begin{tabular}{ccccccccc}
\hline Dosis Fentin Asetat & \multicolumn{7}{c}{ Total Mortalitas (Jam Setelah Aplikasi) } \\
\hline & 6 & 12 & 18 & 24 & 30 & 36 & 42 & 48 \\
\hline $\mathbf{4}$ ppm & 5 & 8 & 9 & 12 & 14 & 14 & 14 & 14 \\
$\mathbf{6}$ ppm & 8 & 9 & 12 & 13 & 14 & 14 & 14 & 14 \\
$\mathbf{8}$ ppm & 10 & 10 & 15 & 22 & 22 & 22 & 22 & 22
\end{tabular}

Sumber: Data primer penelitian 2015

Berdasarkan hasil penelitian dapat dilihat pada Gambar 3. diatas yaitu 6 jam setelah aplikasi, perlakuan A dengan konsentrasi fentin asetat 4 ppm menyebabkan trisipan mati sebanyak 5 ekor, pada perlakuan B dengan kosentrasi fentin asetat 6 ppm menyebabkan 8 ekor trisipan mati, sedangkan pada perlakuan $\mathrm{C}$ dengan konsentrasi fentin asetat tertinggi yaitu 8 ppm reaksi yang ditimbulkan sangat toksik yang menyebabkan 10 ekor trisipan mati. Pada pengamatan kedua yaitu 12 jam setelah aplikasi pada perlakuan A jumlah trisipan yang mati menjadi 8 ekor, sedangkan pada perlakuan B menjadi 9 ekor trisipan mati artinya hanya 1 trisipan yang mati setelah pengamatan pertama, dan pada perlakuan $\mathrm{C}$ jumlah trisipan yang mati tetap berjumlah 10 ekor. Dosis tertinggi yaitu 8 ppm pada paparan selama 24 jam, memberi pengaruh mortalitas tercepat sebagai efek kuat dari konsetrasi moluskisida dengan bahan aktif $60 \%$, dapat diartikan bahwa semakin meningkat dosis pemberian persatuan liter air akan mempercepat respon mortalitas sampel uji/satuan waktu. Jika dibandingkan dengan aflikasi pada ikan Nila dari hasil uji oleh Lukmini (2016) dengan kadar fentin asetat 0,075 ppm dengan paparan selama 24 jam, ikan uji mengalami mortalitas $100 \%$.

Aplikasi pada pukul 18, menunjukkan kematian tertinggi terjadi pada perlakuan $\mathrm{C}$ dengan total mati 15 ekor, artinya terjadi penambahan 5 ekor dari total pengamatan sebelumnya, pada perlakuan B juga mengalami penambahan yaitu 3 ekor sehingga menjadi 12 ekor trisipan yang mati hingga 18 jam setelah aplikasi perlakuan, sedangkan pada perlakuan A hanya bertambah 1 ekor trisipan yang mati. Pengamatan ke empat yaitu 24 jam setelah aplikasi, dapat dilihat pada grafik bahwa perlakuan $\mathrm{C}$ dengan konsentrasi 
fentin asetat tertinggi menunjukkan hasil yang sangat signifikan yang menyebabkan kematian trisipan hingga total 22 ekor, artinya mengalami penambahan 7 ekor trisipan, pada perlakuan A hanya mengalami penambahan 3 ekor trisipan sehingga total 12 ekor trisipan sedangkan pada perlakuan $C$ hanya menyebabkan 1 ekor trisipan mati sehingga total hingga 24 jam setelah aplikasi hanya 13 ekor trisipan yang mati.

Pada pengamatan 30 jam setelah aplikasi pada perlakuan A dan B masing-masing mengalami penambahan kematian yaitu 2 ekor pada perlakuan $A$ dan 1 ekor pada perlakuan B, sedangkan pada perlakuan $C$ tidak mengalami penambahan. Pada pengamatan 36, 42, serta 48 jam setelah aplikasi masing- masing perlakuan tidak mengalami penambahan kematian.

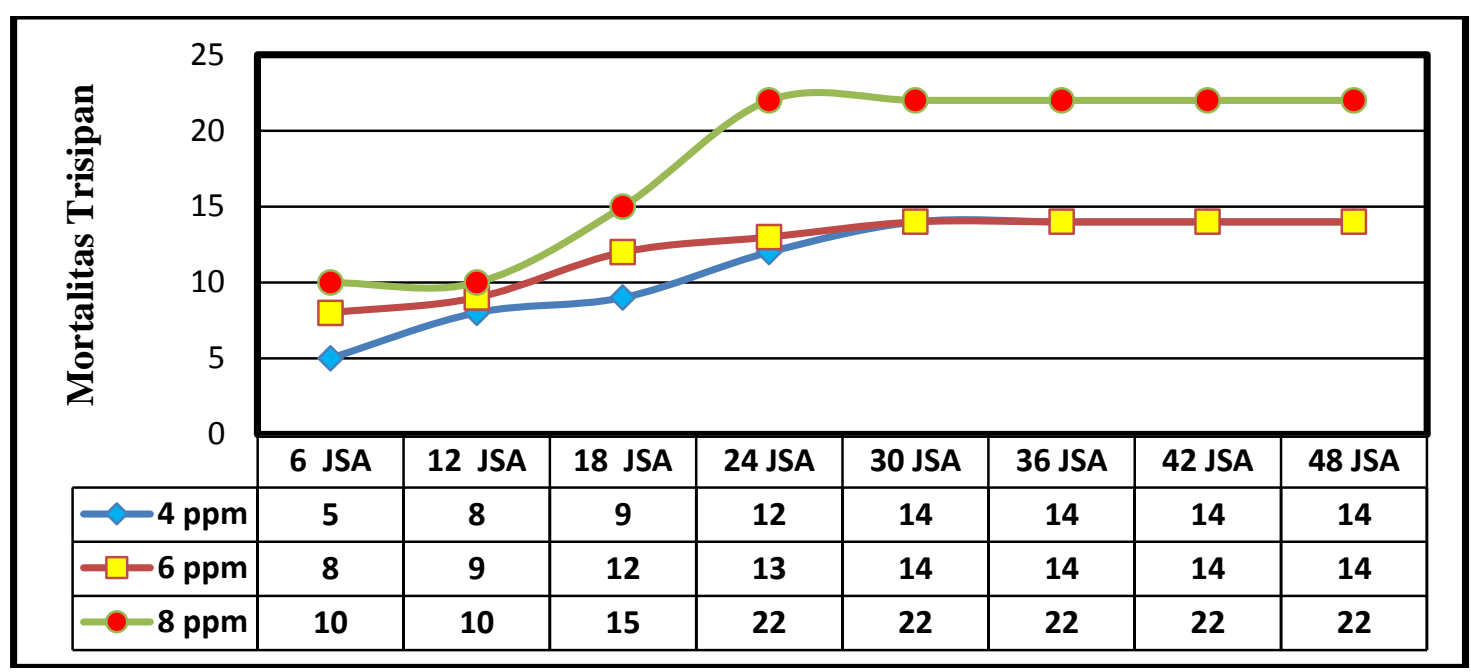

Keterangan: JSA (Jam Setelah Aplikasi)

Gambar 3. Mortalitas trisipan pada perlakuan fentin asetat (Sumber: Data primer2015)

Secara keseluruhan berdasarkan hasil penelitian, perlakuan dengan konsentrasi fentin asetat tertinggi yaitu 8 ppm reaksi yang ditimbulkan sangat toksik dibanding perlakuan dengan konsentrasi fentin asetat 4 ppm, dan 6 ppm. Efek kuat fentin asetat pada konsetrasi 8 ppm mengakibatkan kematian secara langsung pada sampel uji terisipan, yang dibuktikan dengan tidak berfungsinya sistem kerja tubuh dan perubahan cairan dalam organ sebagai respon terhadap bahan toksit, hal ini sejalan perlakuan yang dilalukan oleh Lukmini, dkk, (2016) pada ikan nila, yang menyebabkan adanya penurunan karakter hematologi dan laju pertumbuhan.

Hasil uji sidik ragam yang tersaji pada Tabel 4, yaitu menunjukkan fentin asetat berpengaruh sangat signifikan (nyata) terhadap tingkat kematian trisipan, sehingga dapat disimpulkan bahwa fentin asetat sangat berhasil untuk membasmi hama trisipan dan berarti pula ada salah satu perlakuan yang pengaruhnya sangat menonjol jika dibandingkan dengan pengaruh lainnya. Menurut Koesuemadinata, (2003) bahwa fentin asetat diklasifikasikan kedalam golongan kelas A, yang mana nilai toksisitas tinggi (LC50 < 1 ppm). 
Berdasarkan hasil uji lanjut BNT (Beda Nyata Terkecil) diperoleh hasil perlakuan A dan B tidak berbeda nyata, namun perlakuan A dan B sama sama menunjukkan perbedaan sangat nyata dengan perlakuan $\mathrm{C}$.

Tabel 4. Analisis sidik ragam

\begin{tabular}{lcccccc}
\hline \multicolumn{1}{c}{ Sumber } & $\begin{array}{c}\text { Derajat } \\
\text { Bebas }\end{array}$ & $\begin{array}{c}\text { Jumlah } \\
\text { Kuadrat }\end{array}$ & $\begin{array}{c}\text { Kuadrat } \\
\text { Tengah }\end{array}$ & F.Hitung & \multicolumn{2}{c}{ F.Tabel } \\
Keragaman & 2 & 12.7 & 6.3 & $11.4^{*}$ & $\mathbf{0 . 0 5}$ & $\mathbf{0 . 0 1}$ \\
\hline Perlakuan & 2 & 3.3 & 0.5 & & & 10,92 \\
Galat & 6 & 16 & & & & \\
Total & 8 & \multicolumn{7}{l}{ Keterangan: F Hitung $>$ 0,01 sangat berbeda nyata }
\end{tabular}

\section{Korelasi Fentin Asetat dengan Kualitas Air Media}

Pemberian dosis fentin asetat berbeda dengan kadar kandungan bahan aktif $60 \%$ diindikasikan kualitas air media menggunakan analisis regresi pada setiap farameter kualitas air terukur. Hasil analisis regresi kualitas air media ( $\mathrm{pH}, \mathrm{DO}$, dan suhu) secara berturut dapat dilihat pada Gambar 4, 5, dan 6.

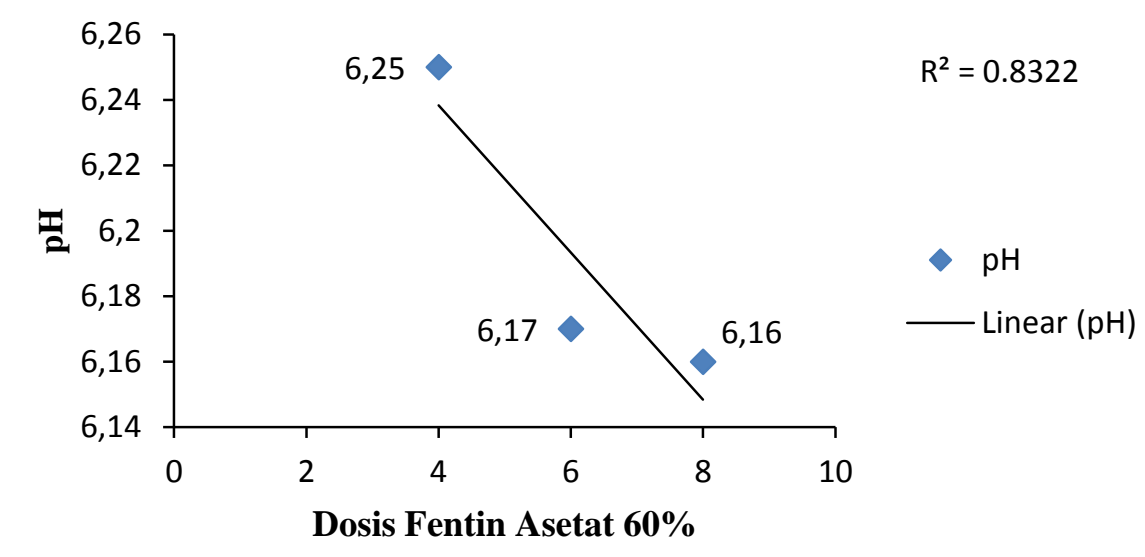

Gambar 4. Hubungan analisa regresi linear dosis fentin asetat $60 \%$ dengan $\mathrm{pH}$ air.

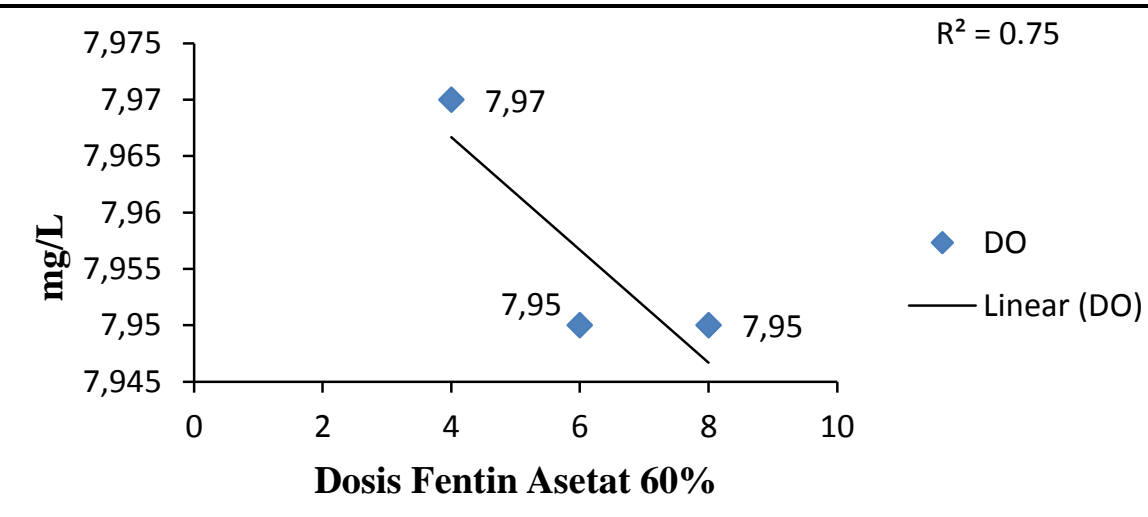

Gambar 5. Hubungan analisa regresi linear dosis fentin asetat $60 \%$ dengan oksigen terlarut 


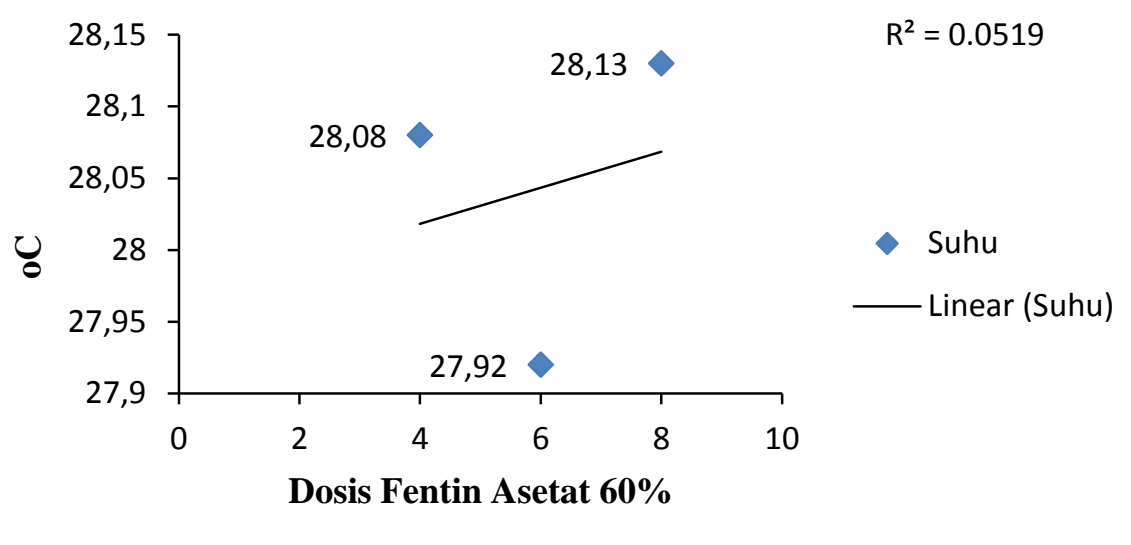

Gambar 6. Hubungan analisa regresi linear dosis fentin asetat $60 \%$ dengan suhu air

Hasil analisis regresi dari hubungan $\mathrm{pH}$ air terhadap dosis fentin asetat $60 \%$ menunjukkan nilai $\mathrm{R}^{2}$ yaitu 0,83 , hubungan fentin asetat $60 \%$ dengan oksigen terlarut nilai $R^{2}$ yaitu 0,75 , dan hubungan fentin asetat $60 \%$ dengan suhu air nillai $R^{2}$ yaitu 0,05 . berdasarkan ketiga korelasi tersebut bahwa pengaruh fentin asetat $60 \%$ terhadap $\mathrm{pH}$ yaitu sangat kuat, sedangkan pengaruhnya terhadap oksigen terlarut yaitu kuat, dan terhadap suhu yaitu sangat rendah. Jadi, dari ketiga parameter kualitas air yang sangat berpengaruh terhadap dosis fentin asetat $60 \%$ yaitu $\mathrm{pH}$ dan oksigen terlarut.

\section{$4 \quad$ Kesimpulan}

Berdasarkan hasil penelitian dan pembahasan dapat diambil kesimpulan sebagai berikut:

1. Pemberian fentin asetat $60 \%$ sangat berpengaruh pada tingkat kematian trisipan

2. Persentase tingkat kematian trisipan (Telescopium-telescopium) tertinggi diperoleh pada perlakuan C (8 gr/l) dan tarendah pada perlakuan A (4 gr/l)

3. Hasil korelasi fentin asetat $60 \%$ dengan $\mathrm{pH}, \mathrm{DO}$, dan suhu, menunjukkan nilai pengaruh yang berbeda secara berturut, diawali $\mathrm{pH}$ dengan nilai. $\mathrm{R}^{2}$ yaitu 0,83 , $\mathrm{DO}$ dengan nilai $R^{2}$ yaitu 0,75 , dan suhu dengan nilai $R^{2}$ yaitu 0,05 .

\section{Daftar Pustaka}

Asep, M. (2011).Pengaruh Molusksida Fentin Asetat 60\% Terhadap Perkembangan Siput Semak (Bradubaena sianilarus ferussac) dan Produksi Tanaman Kubis Bunga (Brassica ocracea Var. botryris L). [Skripsi]. Fakustas Agribisnis dan Rekayasa Pertanian. Universitas Subang.

Budiman, (1991). Penelaan Beberapa Gatra Ekologi Moluska Bakau Indonesia [Desertasi]. Jakarta. Fakultas pascasarjana. Universitas indonesia.

Hamsiah, (2000). Peranan Keong Bakau (Telescopium telescopium L.) sebagai Biofilter dalam Pengolahan Limbah Budidaya Tambak Intensif. [Tesis]. IPB.

Houbrick, R.S. (1991). Systematic Review and Fundamental Morphology of the Mangrove Snail Terebralia and Telescopium (Potamidae; Prosobranchia). Malacologia. 
Departement of Invertebrate Zoology, National Museum of Natural History, Smithisonian Institution, Washinton, D.C. 20560 U.S.A.

Kementerian Pertanian. (2011). Pedoman Umum Skrining Pestisida.Direktorat Jenderal Prasarana dan Sarana.Direktorat Pupuk dan Pestisida.

Koesoemadinata, S. (2003). Metode Standar Pengujian Toksisitas Pestisida terhadap lkan. Komisi Pestisida. Direktorat Jenderal Bina Sarana Pertanian, Departemen Pertanian. Jakarta.

Lukmini, A., Supriyono, E., dan Budiardi, T. (2016). Toksisitas Moluskisida Fentin Asetat terhadap Hematologi dan Pertumbuhan Ikan Nila, Oreocrhomis niloticus (Linnaeus, 1758). Jurnal Iktiologi Indonesia. 17 (1); 1-9.

Munajat, (2011). Pengujian Moluskisida Fentin Asetat 60\% Terhadap perkembangan Siput Semak (Bradybaena similaris ferussac) dan Produksi Tanaman Kubis Bunga (brassica oleraseae Var. L.). Fakultas Agrobisnis dan Rekayasa Pertanian. Universitas Subang. 